\title{
The Performance and Quality of Three Alternative Fruits in the Intermountain West Region of the United States
}

\author{
Esmaeil Fallahi ${ }^{1}$, Bahar Fallahi, Michael J. Kiester, and Shahla Mahdavi \\ University of Idaho, Parma Research and Extension Center, 29603 U of I Lane, Parma, ID 83660
}

Additional index words. asian pear quality evaluation, cold region table grapes, grape adaptability, grape genotype, quince cultivars

\begin{abstract}
Adaptability and feasibility of table grape (Vitis vinifera or Vitis labrusca), asian pear (Pyrus pyrifolia), and quince (Cydonia oblonga) production under the high desert conditions of southwest Idaho in the Intermountain West region of the United States were studied. 'Alborz' table grape was harvested between 1 and 15 Sept. and with proper thinning, this cultivar had outstanding clusters and berries and could be a successful table grape for planting at commercial scales in warmer spots under conditions of this study. 'Kashishi' and 'Autumn Royal' were late-season cultivars and had large berries with excellent quality. 'Ralli', also called 'Anahita' in the Intermountain West, had attractive clusters and berry color, but was sensitive to frost and had poor production. 'Princess' grape was harvested between 5 and 30 Sept. and had poor fruit set, but berries had outstanding flavor. 'Niitaka' asian pear had the largest and firmest fruit with the lowest soluble solids concentration (SSC) among all tested asian pears. 'Semi Dwarf Shinko' asian pear had larger fruit than 'Kikusui' and '20th Century' but smaller than 'Niitaka'. However, 'Kikusui' and '20th Century' had excellent fruit flavor and quality. Thus, 'Kikusui', '20th Century', and 'Niitaka' asian pears can be chosen for planting under condition of this study. 'Aromantnaya' and 'Rich' quinces matured earlier and had lower fruit firmness than other cultivars. These cultivars can be planted for early market. Based on this study, 'Van Deman' can be chosen for fresh consumption if sweet cultivars are in demand by the market. However, 'Rich' and 'Smyrna' quinces can be chosen if fruit with large size and bright yellow color is preferred.
\end{abstract}

Alternative fruit is defined as any fruit grown in an area where it is not grown traditionally. Thus, a fruit or vegetable that is routinely grown in one area could be considered as an alternative crop in another region. As the world population grows and people of different cultural and ethnic backgrounds gather and live in a new region or city, the demand for diversification of fruits and vegetables increases to meet the needs of this new demography. Also alternative fruits have become extremely popular because of their health benefits. In addition to the increasing public demand, the increasing costs of fuel and labor and fluctuating prices of traditional fruits have created challenges for traditional tree fruit growers in recent years. These challenges have resulted in efforts to develop alternative fruit cultivars and to modify cultural practices, to produce cultivars in regions beyond California, to reduce the cost of transportation, and to create a niche market (Fallahi, 2006; Fallahi et al., 2001).

Table grapes are one of the most important alternative fruit crops for many regions and even at a small scale would fit perfectly in the operation of any wine grape and tree fruit grower in the Intermountain West region, which includes Washington, Idaho, Utah, Colorado, and Oregon. Table grapes

Received for publication 29 Dec. 2015. Accepted for publication $11 \mathrm{Feb} .2016$.

This paper was part of the colloquium "Alternative Specialty Crop: Opportunities and Challenges," presented at the 2015 ASHS Conference, New Orleans, LA, on 4 Aug. 2015, and sponsored by the Working Group of Asian Horticulture, Tropical Horticulture Working Group, and Pomology Working Group.

This project was supported by the USDA Specialty Crop Block Grant.

1'Corresponding author. E-mail: efallahi@uidaho. edu.

1320 in this region are harvested when most of the fresh table grapes in California are either finished or are only available in storages.

In the United States, various viticultural and berry sensory characteristics are well documented in California where $V$. vinifera is widely grown (Nelson, 1985; Nelson et al., 1973; Weaver, 1976). However, despite the importance of table grapes as an alternative fruit, berry characteristics and cultural practices are less studied in other states such as Idaho (Fallahi et al., 1995, 2001, 2006), Ohio (Cahoon et al., 1985), Florida (Mortensen and Balerdi, 1974), Canada (British Columbia Ministry of Agriculture, 1993; Reynolds et al., 1992), and Western Oregon (Hemphill et al., 1992).

Fire blight [Erwinia amylovora (Burr.)] is a major limiting problem in the production of european pears (Pyrus communis L.) in the western United States. Fire blight-resistant european pears often are not precocious and productive. In an attempt to improve pollination, precocity, and productivity in fire blighttolerant 'Magness' pear, asian pear trees were used as a pollinizer (Walsh et al., 2015). In this process, they found that asian pears could be planted as a viable alternative crop for local fruit growers. Some asian pear cultivars were tested in Maryland in the 1970s (Oitto et al., 1970), and most of that work focused on older Chinese cultivars, with little testing of japanese and korean juicy pears (Nashi types). Beutel (1990) reported general characteristics of various asian pears. More recently, Walsh et al. (2015) reported that 'Yoinashi', 'Atago', 'Shinko', and 'Olympic' asian pears were well received by consumers.

The quince (Cydonia oblonga Mill.) belongs to the family Rosaceae, subfamily Maloideae along with pears (Pyrus sp.) and apples (Malus sp.). The quince is native to Persia (Iran) and Asia Minor (Westwood, 1978). Quince has numerous uses in the fresh market, processing (such as jam, jellies, and syrup), and medicine in the Middle East, Latin America (particularly Mexico), Europe, and many other regions of the world. However, quinces have been mostly used as pear rootstocks in the Western world (Webster, 1998). Less than 30 or 40 variety names have been documented, and little or no effort has been made to increase the number of varieties (Hedrick, 1925). Morphological characteristics of the fruits and trees of the few known quince varieties are so similar that it is difficult to obtain a reliable classification. A crude attempt was sometimes made by the growers to classify them, such as 'apple-shaped', 'pear-shaped', and 'orange-shaped' (Hedrick, 1925). More recently, some morphological and genetic characteristics were reported in quince, using molecular markers (Yamamoto et al., 2001, 2002a, 2002b, 2002c; 2004).

During the past 26 years, the University of Idaho Pomology and Viticulture Program has experimented with several new fruit crops and as a result, a new alternative fruit industry consisting of different fruits is emerging in Idaho. The goal of this research was to evaluate different cultivars of the three most successful alternative fruits, including table grape, asian pear, and quince for their precocity, productivity, fire blight tolerance, and local consumer acceptance. The results of this research would be valuable to producers in the western United States, and perhaps other areas with similar growing conditions interested in establishing sustainable vineyards and orchards for directmarket sales.

\section{MATERIALS AND METHODS}

General description of the experimental orchard and vineyard. The ground was prepared and fumigated with Toluene 2 before planting, and the experimental vineyard and alternative fruit orchards were established at the University of Idaho Parma Research and Extension Center, near Parma Idaho, United 
States. The experimental site was located at lat. $43.8^{\circ} \mathrm{N}$, long. $116.9^{\circ} \mathrm{W}$, and $673 \mathrm{~m}$ elevation above sea level, with an annual precipitation of about $297 \mathrm{~mm}$ and a sandy loam soil of $\mathrm{pH}$ $\approx 7.3$. A drip irrigation system was installed, and trees and vines were irrigated according to the ETc information provided from the Agrimet Weather Station at the University of Idaho Parma location. Materials were gathered from unique but reliable nurseries in the United States.

Grape cultivar evaluation. Several cultivars, including 'Alborz' (a mutation of 'Flame Seedless'), 'Emerald', 'Ralli' (also called 'Anahita' in the Intermountain West), 'Autumn Royal', 'Princess', 'Kashishi', 'Neptune', 'Red Globe', 'Flame', and 'Jupiter' were propagated and planted at $1.8 \times 2.7 \mathrm{~m}$ in Spring 2002 . The vines were trained into bilateral cordon canopy system. General cultural practices were similar to the guidelines established in California but modified to suit the local growth cycle and conditions (Fallahi et al., 2011).

Vine survival after each winter was monitored, and cold tolerance of each grape was determined. Table grape fruit quality attributes, including berry size, color, berry skin characteristics, and cluster weight at harvest, were measured according to the procedures described by Fallahi et al. (2011). Five vines of each cultivar were sprayed with gibberellic acid (GA) three times, each time at $50 \mathrm{ppm}$. The first spray was made at the beginning of fruit set (berries at about $4 \mathrm{~mm}$ ) and the second and third GA sprays were applied at a weekly interval after the first spray.

Since 'Alborz' was found to be the most important cultivar in our first phase of evaluation, further detailed studies were conducted on this cultivar. For this purpose, dates for bloom, fruit set, girdling, and cluster tipping and/or removal and times for GA sprays in 'Alborz' were recorded over 8 years between 2000 and 2007. For this objective, one-third of the tip of each cluster was removed, and the number of clusters was adjusted to have a maximum of 20 clusters/vine when vines were young and 28 clusters/vine when they were mature.

Asian pear and quince cultivar evaluation. Five asian pears on $\mathrm{OH} \times \mathrm{F}$ rootstock and five cultivars of quince on Quince A rootstock were obtained from Orange County Nursery (Orange County, CA) and planted at $2.4 \times$ $4.9 \mathrm{~m}$ spacing in Spring 2002. Trees were trained into a vase shape or multiple leaders, with four to five main limbs, in March every year. General cultural practices were similar to the guidelines established in California but modified to suit the local growth cycle and conditions. Asian pear and quince fruits were not thinned.

Tree growth, survival, bloom date, harvest date, yield, and many other pomological characteristics of all asian pear and quince cultivars were recorded annually. Twenty fruits were randomly sampled from each tree at harvest during 2004-05. For quality evaluation at harvest, fruits were gently wiped with a damp cloth and percentage of fruit with visible russet was recorded. Fruits were weighed and skin color was visually ranked on a scale of 1 to 5 , with $1=$ poor yellow color, progressively to $5=100 \%$ yellow. Soluble solids concentration (SSC) was measured using a temperature-compensated refractometer (Atago N1, Tokyo, Japan) and fruit firmness was measured, using an 11-mm probe for quinces and a 7.9-mm probe for asian pears, with a Fruit Texture Analyzer (Guss, Strand, Western Cape, South Africa).

Experimental designs and statistics. The experiment was arranged based on a completely randomized design for grapes, asian pears, and quinces. There were seven blocks, each with two trees or vines for table grape, asian pear, and quince. The assumption of normal data distribution was checked by performing univariate analyses for all vine and tree responses in this study.

Analyses of variance were conducted using SAS (SAS Institute, 2007), with PROC GLM and means separated using Fisher's protected least significant difference at $P \leq$ 0.05 .

\section{RESULTS AND DISCUSSION}

Table grape cultivar evaluation. 'Alborz', 'Ralli' ('Anahita'), 'Autumn Royal', and 'Kashishi' had excellent flavor and berry size (Table 1). 'Autumn Royal' and 'Kashishi' were late-season grapes and matured between 10 Sept. and 15 Oct. and tasted best between 1 and 20 Oct. (Table 1; Fig. 1, group 1). 'Kashishi' is a seeded grape and could replace 'Red Globe' in the market in the Intermountain West region due to its superior flavor, medium-size cluster, and berry shape. However, production of both 'Kashishi' and 'Anahita' diminished in the past 3 years due to cold sensitivity of these cultivars in the winter and spring. It seems that 'Anahita' would respond much better in an area with higher temperatures, and this needs to be examined. Production in 'Autumn Royal' was low and inconsistent.

We performed a heavy shoot thinning in both 'Alborz' and 'Emerald', and the incidence of powdery mildew was reduced by about $30 \%$ to $60 \%$, depending on the season and canopy growth (data not shown). 'Alborz' grape could be harvested between 1 Sept. and 10 Oct. 'Alborz' berries were red to maroon and could turn deep maroon if clusters remained on the vine. Properly managed 'Alborz' grape always had sufficient SSC after berries had complete color. Thus, 'Alborz' can be harvested based on the market preference for the degree of redness for berry color without the need for color-promoting agents in the Intermountain West. These berries were seedless and extremely crunchy and remained crunchy as long as clusters stayed on the vine. There was no shattering in the berries of 'Alborz'.

Our study showed that 'Emerald' did not benefit from GA application. In fact, sometimes GA left undesirable marks on the 'Emerald' berries, and these marks were more evident when a "bilateral cordon" rather than a quadrilateral/divided canopy system was used (data not shown). The most successful 'Emerald' crop was produced when we applied fungicides for powdery mildew every 12 to $14 \mathrm{~d}$ throughout the season.

'Princess' was harvested between 5 and 30 Sept. (Table 1). This grape had outstanding flavor but the fruit set was low and clusters were rather small (268 g). We also found that 'Princess' table grape did not favor GA sprays. 'Princess' grape showed marginal leaf chlorosis that started at fruit set and

Table 1. Summary of various characteristics of the table grape cultivars

\begin{tabular}{|c|c|c|c|c|c|c|c|c|c|}
\hline Cultivar & Seed $^{\mathrm{z}}$ & $\begin{array}{l}\text { Berry } \\
\text { wt }(g)\end{array}$ & Cluster wt (g) & $\begin{array}{l}\text { Berry } \\
\text { Color }\end{array}$ & Harvest date & Skin $^{y}$ & GA need & Overall & Comments \\
\hline Alborz & SL & 5.07 & 534 & MR & 1 Sept.-15 Sept. & $\mathrm{T}$ & Yes & Excellent & Needs crop management \\
\hline Anahita & $\mathrm{SL} / \mathrm{T}$ & 5.24 & 526 & $\mathrm{RM}$ & 1 Sept.-30 Sept. & $\mathrm{T}$ & Yes & Excellent & Sensitive to spring frost \\
\hline Autumn Royal & SL & 7.03 & 703 & B & 15 Sept.-15 Oct. & $\mathrm{T}$ & Yes & Excellent & Mild sunburn \\
\hline Princess & SL & 6.55 & 268 & G & 5 Sept.-30 Sept. & $\mathrm{T}$ & No & Excellent & Poor fruit set \\
\hline Kashishi & $\mathrm{SD}$ & 8.19 & 522 & M & 15 Sept.-15 Oct. & $\mathrm{T}$ & Yes & Excellent & Pleasant taste \\
\hline Emerald & SL & 4.60 & 837 & G & 10 Sept.-15 Oct. & $\mathrm{T}$ & No & Excellent & High sunburn and powdery mildew \\
\hline Neptune & SL & 4.11 & 210 & G & 5 Sept. -5 Oct. & $\mathrm{S}$ & Yes & Medium & Nice berries, muscat flavor \\
\hline Red Globe & $\mathrm{SD}$ & 7.10 & 530 & $\mathrm{R}$ & 20 Sept. -20 Oct. & $\mathrm{T}$ & Yes & Medium & Late season \\
\hline Flame & SL & 5.06 & 529 & MR & 1 Sept.-15 Sept. & $\mathrm{T}$ & Yes & Excellent & Needs crop management \\
\hline Jupiter & $\mathrm{SL} / \mathrm{T}$ & 4.10 & 204 & DP & 1 Sept.-15 Oct. & $\mathrm{T}$ & Yes & Excellent & High yield, cold tolerant, fresh, and raisins \\
\hline $\operatorname{LSD}(5 \%)$ & & 1.0 & 102 & & & & & & \\
\hline
\end{tabular}

LSD $=$ least significant difference.

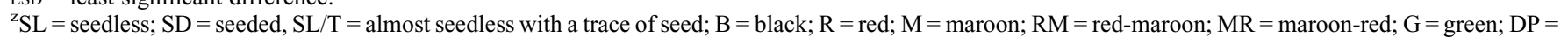
deep purple.

${ }^{\mathrm{y}} \mathrm{T}=$ tender skin; $\mathrm{S}=$ slip skin. 
continued throughout the season. The symptoms were consistent with potassium $(\mathrm{K})$ deficiency. In two seasons, we applied high levels of $\mathrm{K}$ (about $30 \mathrm{~g} \mathrm{~K}$ as $\mathrm{KCl} /$ vine). This application reduced the poor fruit set problem to some extent (data not shown), and this area deserves further research. Based on this study, 'Princess' is not recommended until the fruit set problem is resolved.

'Jupiter' showed more tolerance to subfreezing temperatures and showed no frost damage during many years of our evaluation. Berry size was improved drastically with some cluster removal and by using a quadrilateral/ divided canopy rather than a bilateral cordon (data not shown). 'Neptune' clusters size and berry weight was comparable with those of 'Jupiter'; however, berry flavor in 'Jupiter' was superior to that of 'Neptune'. Although 'Neptune' produced attractive small clusters with virtually no shatter, the berries had a strong "foxy" aftertaste and were unpleasant to most consumers.

Crop adjustment and phenological dates in 'Alborz' grape. 'Alborz' clusters had an average weight of $534 \mathrm{~g}$ with an average berry weight of $5.07 \mathrm{~g}$ (Table 1) and berries were large enough to put 'Alborz' in the large berry size category for "flame type" grapes in the commercial grape market.

In a different study, various cluster management practices were performed on 'Alborz'. In that study, vines that received cluster shortening and cluster removal plus girdling had significantly larger berries than control vines (data not shown). We concluded that both cluster removal and cluster shortening are essential for obtaining large berries.

Dates for the late-dormant spray (when buds just started to burst) varied between 3 and 13 Apr. during the 2000 and 2007 period (Table 2). During this period, dates of full bloom were between 9 and 17 June, and dates for shoot thinning, cluster thinning, and tip shortening were between 12 June and 1 July (Table 2). During these dates, shoots were about 50 to $65 \mathrm{~cm}$ long. Starting in 2007, we thinned shoots at earlier dates than before, when shoots were about 35 to $45 \mathrm{~cm}$ long (data not shown). It was easier to thin shoots when they were shorter and adjust the clusters later, when fruit set had taken place. Dates for the first GA applications were usually close to the shoot and cluster thinning dates between 2000 and 2007 (Table 2).

Application of GA at $50 \mathrm{ppm}$ was the optimum rate for 'Alborz' table grape. Although application of GA at $60 \mathrm{ppm}$ resulted in large berries as compared with control, berry color was delayed or stayed green in some years (data not shown).

Asian pear cultivar evaluation and recommendation. 'Niitaka' asian pear was

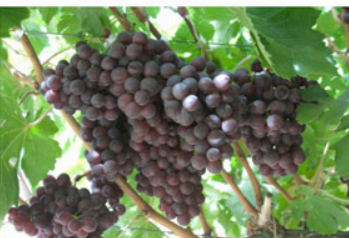

'Alborz' cut cluster

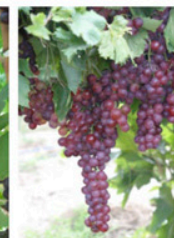

'Alborz'

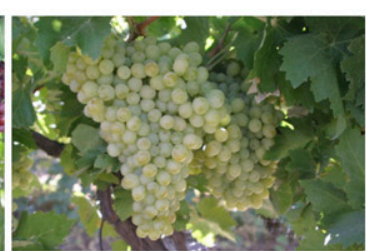

'Emerald'

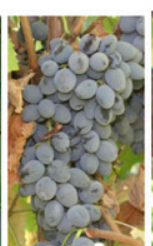

'Jupiter'

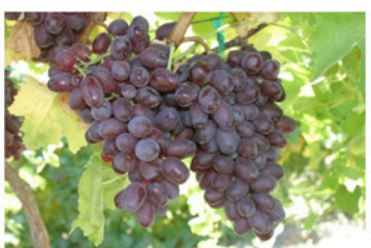

'Kashishi'

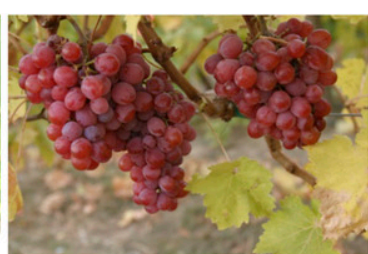

'Ralli’ ('Anahita')

Photos of Group 1: Photos of important table grapes grown at the University of Idaho, Parma, Idaho, USA.

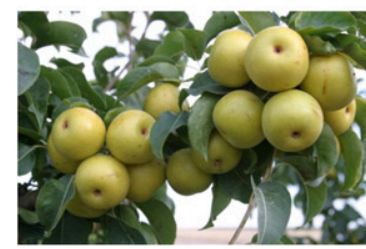

'Kikusui'

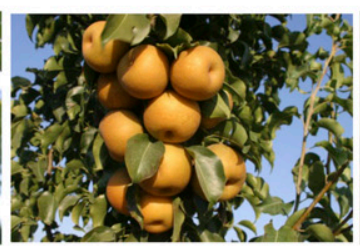

'Niitaka'

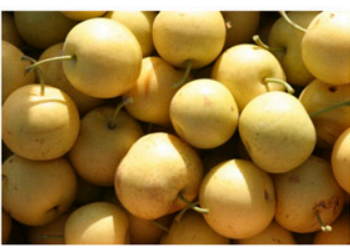

'20 ${ }^{\text {th }}$ Century'

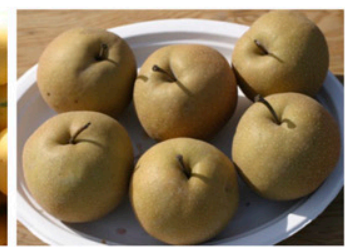

'Semi Dwarf Shinko'

\section{Photos of Group 2: Photos of important Asian pear fruit and blossom at the University of Idaho, Parma, Idaho, USA.}

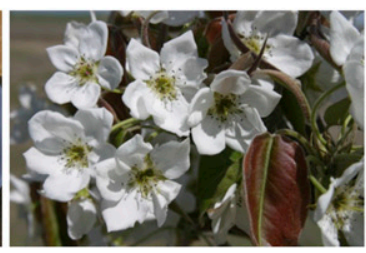

'Full Bloom'

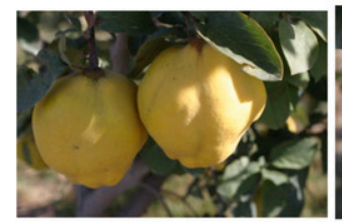

'Rich'

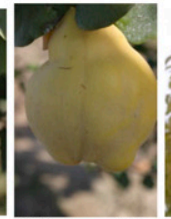

'Kaunching'

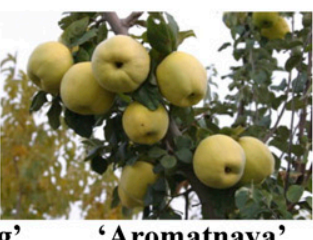

'Aromatnaya'

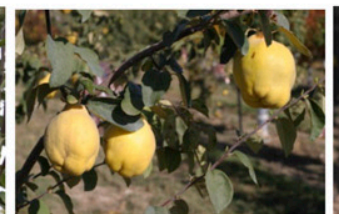

'Smyrna'

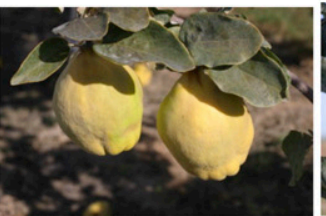

'Van De man'

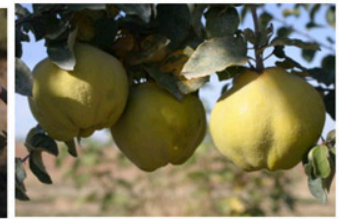

'Dwarf Pine'

Photos of Group 3: Photos of important quince fruit grown at the University of Idaho, Parma, USA.

Fig. 1. Grapes (top), asian pear fruit (middle), and quince fruit (bottom) grown at the University of Idaho, Parma.

Table 2. Date of dormant spray, full-bloom, shoot thinning, cluster adjustment, girdling, and gibberellic acid (GA) sprays in 'Alborz' table grape in southwest Idaho, United States, during 2002-07.

\begin{tabular}{|c|c|c|c|c|c|c|c|}
\hline $\mathrm{Yr}$ & Dormant spray & Full bloom & Shoot and Cluster adjustment ${ }^{z}$ & Girdling & First GA & Second GA & Third GA \\
\hline$\overline{2000}$ & 3 Apr. & 10 June & 21 June & 21 June & 20 June & 27 June & 3 July \\
\hline 2002 & 7 Apr. & 14 June & 25 June & 25 June & 24 June & 2 July & 9 July \\
\hline 2003 & 9 Apr. & 14 June & 25 June & 25 June & 24 June & 1 July & 9 July \\
\hline 2005 & 5 Apr. & 17 June & 1 July & 1 July & 1 July & 8 July & 14 July \\
\hline 2006 & 13 Apr. & 9 June & 16 June & 16 June & 18 June & 28 June & 5 July \\
\hline 2007 & 6 Apr. & 8 June & 12 June & 16 June & 15 June & 22 June & 28 June \\
\hline
\end{tabular}

${ }^{\mathrm{z}}$ Actual shoot and cluster adjustment $=$ the actual date that we removed the excess shoots and clusters and shortened $1 / 3$ to $1 / 2$ of the remaining ones.

Note: we could have actually removed the excess shoots a few days earlier for a smoother operation and better results, because shoots were shorter. We also found that the follow up GA could have been applied within $4-5 \mathrm{~d}$ of the previous one. 
Table 3. Effect of asian pear cultivars on date of harvest, average fruit quality attributes, and yield in southwest Idaho, United States, over 2 years.

\begin{tabular}{|c|c|c|c|c|c|c|c|}
\hline \multirow[b]{2}{*}{ Cultivar } & \multicolumn{2}{|c|}{ Date of harvest } & \multirow[b]{2}{*}{ Fruit wt (g) } & \multirow[b]{2}{*}{ Color $(1-5)^{\mathrm{y}}$} & \multirow{2}{*}{$\begin{array}{l}\text { Soluble solids } \\
\left.\text { concn ( }{ }^{\circ} \text { Brix }\right)\end{array}$} & \multirow[b]{2}{*}{ Firmness (N) } & \multirow{2}{*}{$\begin{array}{c}\text { Yield avg 2004-05 } \\
(\mathrm{kg} / \text { tree })\end{array}$} \\
\hline & 2004 & 2005 & & & & & \\
\hline Niitaka & 5 Oct. & 21 Sept. & $253.2 \mathrm{a}^{\mathrm{z}}$ & $2.91 \mathrm{c}$ & $11.56 \mathrm{c}$ & $37.7 \mathrm{a}$ & $16.23 \mathrm{a}$ \\
\hline Semi-Dwarf Shinko & 5 Oct. & 27 Sept. & $229.5 \mathrm{~b}$ & $3.68 \mathrm{~b}$ & $12.66 \mathrm{~b}$ & $32.7 \mathrm{~b}$ & $15.01 \mathrm{a}$ \\
\hline Semi-Dwarf 20th Century & 13 Sept. & 21 Sept. & $204.1 \mathrm{c}$ & $4.44 \mathrm{a}$ & $12.70 \mathrm{~b}$ & $27.5 \mathrm{c}$ & $17.46 \mathrm{a}$ \\
\hline Kikusui & 13 Sept. & 21 Sept. & $176.2 \mathrm{~d}$ & $3.84 \mathrm{~b}$ & $14.22 \mathrm{a}$ & $27.9 \mathrm{c}$ & $15.96 \mathrm{a}$ \\
\hline
\end{tabular}

${ }^{\mathrm{z}}$ Mean values within columns followed by the same letter are not significantly different at $5 \%$ level.

${ }^{\mathrm{y}}$ Color rating: $1=$ least yellow, progressively to $5=$ most yellow.

Table 4. Effect of quince cultivars on average yield and fruit quality attributes in southwest Idaho, United States, over 2 years.

\begin{tabular}{|c|c|c|c|c|c|c|c|}
\hline Cultivar & $\begin{array}{c}\text { Date of harvest } \\
2004\end{array}$ & $\begin{array}{c}\text { Date of harvest } \\
2005\end{array}$ & Fruit wt (g) & Color $(1-5)^{\mathrm{y}}$ & $\begin{array}{l}\text { Soluble solids } \\
\text { concn ( }\left({ }^{\circ} \text { Brix }\right)\end{array}$ & Firmness (N) & Yield (kg/tree) \\
\hline Aromatnaya & 5 Oct. & 21 Sept. & $405.5 b^{z}$ & $3.95 \mathrm{c}$ & $12.18 \mathrm{~b}$ & $90.5 \mathrm{c}$ & $13.3 \mathrm{a}$ \\
\hline Rich & 25 Oct. & 20 Oct. & $636.4 \mathrm{a}$ & $4.50 \mathrm{a}$ & $13.08 \mathrm{ab}$ & $122.2 \mathrm{c}$ & $12.6 \mathrm{a}$ \\
\hline Smyrna Century & 25 Oct. & 20 Oct. & $544.1 \mathrm{a}$ & $4.48 \mathrm{a}$ & $13.02 \mathrm{ab}$ & $127.6 \mathrm{bc}$ & $11.4 \mathrm{a}$ \\
\hline Van Deman & 25 Oct. & 20 Oct. & $611.9 \mathrm{a}$ & $4.38 \mathrm{ab}$ & $13.27 \mathrm{a}$ & $129.0 \mathrm{~b}$ & $10.9 \mathrm{ab}$ \\
\hline Dwarf Pine Apple & 25 Oct. & 20 Oct. & $425.8 \mathrm{~b}$ & $2.56 \mathrm{~d}$ & $12.78 \mathrm{ab}$ & $137.3 \mathrm{a}$ & $7.9 \mathrm{~b}$ \\
\hline Kaunching & 25 Oct. & 20 Oct. & $271.1 \mathrm{c}$ & $4.06 \mathrm{bc}$ & $13.73 \mathrm{a}$ & $132.8 \mathrm{ab}$ & $3.5 \mathrm{c}$ \\
\hline
\end{tabular}

${ }_{\mathrm{z}}$ Mean values within columns followed by the same letter are not significantly different at $5 \%$ level.

${ }^{\mathrm{y}}$ Color rating: $1=$ least yellow, progressively to $5=$ most yellow.

harvested on 5 Oct. 2004 and 2 Sept. 2005 and had "candy-sweet" flavor, orange-brown highly russetted fruit with sweet juicy flesh. 'Niitaka' had significantly larger (heavier) fruit than all other tested asian pears in this study (Table 3; Fig. 1, group 2). Fruit size usually has a negative correlation with fruit firmness in apples (Fallahi et al., 1997). However, 'Niitaka' fruit was the firmest while its size was the largest among all tested asian pears (Table 4). The high firmness of this fruit could be due to high calcium content or lower ethylene production and slower polygalacturonase activity as described for apples (Fallahi et al., 1997), and this area deserves further study.

Fruits of 'Niitaka' were highly russetted and had orange-brown color. Since we compare all cultivars with the same scale (1-5) for color and this scale gave a rating of 1 to the least yellow color and 5 to the yellowest fruit, 'Niitaka' fruit had the lowest rate (Table 3). 'Niitaka' had the lowest SSC as compared with other pears. This cultivar had excellent storage life and could be kept in the storage without significant changes in flavor for several months. Based on the results of this study, 'Niitaka' asian pear can also be chosen for its large size, high firmness, attractive color, pleasant flavor, and great storage life.

Color and flavor of fruits in '20th Century' and 'Kikusui' asian pears were more similar than other cultivars; however, fruit size in 'Kikusui' was smaller and SSC was higher than those in all other cultivars. In numerous taste-testing evaluations, 'Kikusui' fruit was ranked as the most popular asian pear among all tested cultivars (data not shown). People chose this fruit over others for its extraordinary pleasant flavor in spite of its smaller size. In a different experiment, we found that fruit size of 'Kikusui' and '20th Century' could be improved by fruit thinning when fruits are about $12 \mathrm{~mm}$ in diameter (data not shown). Thus, 'Kikusui', '20th Century', and 'Niitaka' can be chosen for planting under condition of this study.
'Semi-dwarf Shinko' trees showed relative resistance to fire blight (data not shown). This cultivar was harvested on 5 Oct. 2004 and 27 Sept. 2005 and had larger fruit than 'Kikusui' and '20th Century' but smaller than 'Niitaka' (Table 3). Considering all factors including taste, 'Semi-dwarf Shinko' was found to be the least favorite asian pear by our taste panel in different years (data not shown). Nevertheless, many consumers like the flavor and brown to golden brown color of 'Semidwarf Shinko' when fruit are ripe.

Quince cultivar evaluation and recommendation. 'Aromatnaya' quince had higher yield, lower SSC, and firmness than other cultivars, although the differences were not always significant (Table 4; Fig. 1, group 3). Fruit in this cultivar had lower firmness and were harvested earlier than other cultivars (Table 4). Even earlier harvest did not result in higher fruit firmness in 'Aromatnaya' (data not shown). 'Aromatnaya' fruit had pleasant flavor and could be eaten fresh. 'Aromatnaya' had a short window for harvest and fruit turned brown under the skin if they were harvested shortly after an optimum maturity. Therefore, the storage life in this cultivar was very short (data not shown). Considering all yield and fruit quality attributes, 'Aromatnaya' quince should be chosen for fresh consumption and early market.

Fruits of 'Rich', 'Smyrna', and 'Van Deman' had statistically similar size, color, SSC, and yield (Table 4). Although harvest dates for 'Rich' was similar to 'Smyrna', 'Rich' seemed to mature earlier and had lower firmness than 'Van Deman', 'Dwarf Pine Apple', and 'Kauching' (Table 4). Both 'Smyrna' and 'Rich' quince fruits had slightly acidic "background taste" that was pleasant to those who prefer moderately acidic fruit. Overall, 'Smyrna' and 'Rich' quinces both can be good choices for planting under conditions of this experiment.

Fruits of 'Van Deman' and 'Kaunching' were less acidic (data not shown) and had sweeter fruit than 'Aromatnaya' (Table 4). However, 'Kaunching' quince trees had poor growth and performance throughout this study. This cultivar had smaller fruit and lower yield than all other tested cultivars (Table 4). Because of these characteristics, 'Kaunching' is not recommended for planting in southwest Idaho. While 'Van Deman' quince fruit tended to have "woody" texture, this cultivar can be used by those who prefer sweeter fruit.

Fruits of 'Dwarf Pine Apple' did not develop full yellow color even if the fruit were left on the tree until the end of the growing season. These fruits had significantly higher firmness than all cultivars other than 'Kaunching'. Considering all of these factors, 'Dwarf Pine Apple' is not recommended for planting under conditions similar to those in the Intermountain West region.

\section{CONCLUSIONS}

This study revealed that 'Alborz' can be grown in the Intermountain West region at a large scale for both domestic and export markets, if grown in warmer places. 'Emerald' and 'Autumn Royal' can also be grown commercially in the region. However, each of these cultivars has its own challenges and needs for cluster and shoot thinning.

Overall, 'Kikusui', '20th Century', and 'Niitaka' asian pears can be grown in the Intermountain West region. 'Smyrna' and 'Van Deman' quinces can be grown for late season, but 'Aromatnaya' and 'Rich' quinces can be recommended for early market in the Intermountain west region of the United States. This study underscores the needs for further research projects on evaluating newer cultivars and cultural practices and understanding the environmental reactions in the region.

\section{Literature Cited}

Beutel, J.A. 1990. Asian pears, p. 304-309. In: J. Janick and J.E. Simon (eds.), Advances in new crops. Timber Press, Portland, OR.

British Columbia Ministry of Agriculture. 1993. Fisheries and food. Grape production guide. Extension Systems Branch, Victoria, BC. 
Cahoon, G.A., L.G. Anderson, G.R. Passewitz, D.E. Hahn, A.E. Oden, and R. ZhaoGruber. 1985. Fresh market grapes from Ohio vineyards. Ohio Report May-June, 37-40.

Fallahi, E. 2006. Table grape variety evaluation and improving berry quality, size, and yield, under desert conditions of the Pacific Northwest. Proceeding of the Northwest Center for all Fruit Research 14th Annual Conference, 72-73.

Fallahi, E., W.S. Conway, K.D. Hickey, and C.E. Sams. 1997. The role of calcium and nitrogen in postharvest quality and disease resistance of apples. HortScience 32:831-835.

Fallahi, E., B. Fallahi, and I.J. Chun. 2001. Adaptation, maturity, and fruit quality of table grapes in the Intermountain West region of the U.S.A. J. Small Fruit Rev. 1:29-42.

Fallahi, E., B. Fallahi, M.J. Kiester, and T.M. Elias. 2011. Systematic evaluation of table grapes in search of suitable cultivars for high deserts in the United States. J Appl. Hort. 13:96-100.

Fallahi, E., H. Heydari, and M. Kilby. 1995. Maturity, quality, and production of 'Thompson Seedless' grape as affected by frequency of Gibberellic acid with and without naphthalene acetic acid. J. Small Fruit Viticult. 3:49-61.

Hedrick, U.P. 1925. Systematic pomology. The Macmillan Company, NY.

Hemphill, D.D., W.A. Sheets, and L.W. Martin. 1992. Seedless table grapes for Willamette Valley. Special Report 893. Oregon State University Ag. Expt., St. Corvallis, OR.
Mortensen, J.A. and C.F. Balerdi. 1974. Muscadine grapes for Florida: Yields and other characteristics of 48 cultivars. Proc. Fla. State Hort. Soc. $86: 338-341$

Nelson, K.E. 1985. Harvesting and handling California table grapes for market. Univ. Calif. Agr. Expt. Sta. Bul. 1913.

Nelson, K.E., J.W. Allen, and H.G. Schultz. 1973. Effect of grape maturity, sample, order and sex of the taster on the flavor response of supermarket consumers. Amer. J. Enol. Viticult. 23:86-95.

Oitto, W.A., T. van der Zwet, and H.J. Brooks. 1970. Rating of pear cultivars for resistance to fire blight. HortScience 5:474-476.

Reynolds, A.G., D.A. Wardle, C. Zurowski, and N.E. Looney. 1992. Phenylureas CPPU and thidiazuron affect yield components, fruit composition, and storage potential of four seedless grape selections. J. Amer. Soc. Hort. Sci. 117:85-89.

SAS Institute. 2007. SAS/STAT1 user's guide. Version 9.2, SAS Institute, Cary, NC.

Walsh, C.S., J.M. Harshman, A.E. Wallis, A.B Williams, M.J. Newell, and G.R. Welsh. 2015. Field performance of Asian pear cultivars in the hot, humid summer conditions of the MidAtlantic Region of the United States. T. Deckers and J. Vercammen (eds.) Proc. XII International Pear Symposium. Acta Hort 1094:103-110.

Weaver, R.J. 1976. Grape growing. Wiley-Interscience Publication, New York, London, Sydney, Toronto.
Webster, A.D. 1998. A brief review of pear rootstock development. Acta Hort. 475:135142 .

Westwood, M.N. 1978. Temperate-zone pomology. W.H. Freeman and Company, San Francisco, CA.

Yamamoto, T., T. Kimura, Y. Ban, M. Shoda, T. Hayashi, and N. Matsuta. 2002a. Development of microsatellite markers in Japanese pear (Pyrus pyrifolia Nakai). Mol. Ecol. Notes 2:14-16.

Yamamoto, T., T. Kimura, Y. Sawamura, K. Kotobuki, Y. Ban, T. Hayashi, and N. Matsuta. 2001. SSRs isolated from apple can identify polymorphism and genetic diversity in pear. Theor. Appl. Genet. 102:865-870.

Yamamoto, T., T. Kimura, Y. Sawamura, T. Manabe, K. Kotobuki, T. Hayashi, Y. Ban, and N. Matsuta. 2002b. Simple sequence repeats for genetic analysis in pear. Euphytica 124:129-137.

Yamamoto, T., T. Kimura, M. Shoda, T. Imai, T. Saito, Y. Sawamura, K. Kotobuki, T. Hayashi, and N. Matsuta. 2002c. Genetic link-age maps constructed by using an interspecific cross between Japanese and European pears. Theor. Appl. Genet. 106:9-18.

Yamamoto, T., T. Kimura, J. Soejima, T. Sanada, Y. Ban, and T. Hayashi. 2004. Identification of Quince varieties using SSR markers developed from pear and apple. Breed. Sci. 54:239-244. 